7. Reprod. Fert. (1969) 19, 133-141

\title{
EFFECT OF AN INTRA-UTERINE DEVICE ON MENSTRUAL PERIODICITY IN THE RHESUS MONKEY
}

\author{
P. EGKSTEIN, W. A. KELLY* AND J. H. MARSTON† \\ Department of Anatomy, Medical School, Birmingham 15
}

(Received 5th Fuly 1968)

\begin{abstract}
Summary. This paper describes the techniques used in preparing and supervising rhesus monkeys during a series of experiments to investigate the effects of an intra-uterine device (IUD) upon the processes of conception.

Observations made in the course of these experiments established that the presence of an IUD had no biologically significant effect on either the periodicity or the duration of menstruation.
\end{abstract}

\section{INTRODUCTION}

Although the subject of intra-uterine contraception has been extensively reviewed (Tietze \& Lewit, 1962; Segal, Southam \& Shafer, 1965; Guttmacher, 1965), and the contraceptive efficiency of intra-uterine devices (IUDs) has been clearly established (Tietze, 1966; WHO, 1968), the exact mode of action of IUDs has not been defined.

Comparative experimental studies of the effects of IUDs in a number of mammalian species have been undertaken, in the hope that they might provide some evidence as to possible effects of IUDs in women (cf. reviews by Marston \& Kelly, 1966; Eckstein, 1967; Kar, 1967; Corfman \& Segal, 1968). Clinical studies of women fitted with IUDs have provided variable information, but the scope of such studies is necessarily limited by ethical considerations. An alternative approach is to undertake experimental studies that cannot be performed in women in a sub-human, primate species.

The rhesus monkey (Macaca mulatta) is the most thoroughly studied subhuman primate (Asdell, 1965). Although there are important differences between the two species in the gross anatomy of the reproductive tract (Eckstein \& Zuckerman, 1956), and in the process of implantation and placentation (Ramsey \& Harris, 1966), the physiology of the menstrual cycle, ovulation, fertilization and egg transport into the uterus does appear to be similar in both women and the rhesus monkey. The rhesus monkey must, therefore, be considered one of the most suitable experimental animals for comparative studies on the contraceptive action of IUDs.

* Present address: Department of Anatomy, The University, Bristol BS8 1TD.

$\uparrow$ Present address: Physiological Laboratory, Cambridge CB2 3EG. 
This paper is the first of a series of communications on the effects of IUDs on the reproductive physiology of the rhesus monkey. It reports our observations on menstrual periodicity in the presence of an IUD and presents details of the techniques used in preparing and supervising the female monkeys used in the present series of experiments.

\section{METHODS}

\section{Animals}

The series of experiments was begun in June 1963, using twelve mature, female rhesus monkeys (Macaca mulatta) from the primate colony maintained in this Department. Up to January 1968, 105 additional monkeys were purchased from commercial dealers and used in the various experimental studies.

With the exception of one animal born and reared in the colony, the experimental monkeys had originally been trapped from the wild in various parts of the Indian sub-continent, and on arrival in the primate colony they appeared to be sexually mature. The monkeys weighed from 3.5 to $7.0 \mathrm{~kg}$ and had full, permanent dentitions.

On arrival, forty-four monkeys were pregnant; ten were known to be recently post partum or post abortum, and sixty-two were not pregnant. Most of the non-pregnant monkeys (over $90 \%$ ) were probably parous as judged by examination of their genital tract (either at laparotomy or autopsy) and by the condition of their nipples.

Twenty of the pregnant monkeys delivered full-term infants within $4 \frac{1}{2}$ months of arriving in the colony. Eighteen animals aborted within 2 months, and the remaining six monkeys were subjected to hysterotomy and removal of the foetus in the course of other experiments. The live-born infants were usually separated from their mothers within 21 days of birth.

The single female born and reared in the colony was nulliparous and 7 years old when used for experiment.

\section{Management}

Before being admitted to the colony, all the newly imported animals were conditioned in quarantine for a period of 4 to 6 weeks.

The primate colony houses up to 170 monkeys in one large room, which is air conditioned and maintained at a temperature of $72^{\circ} \mathrm{F}\left( \pm 2^{\circ}\right)$. The lighting system is not precisely controlled and so the light environment reflects the natural variation in day length. However, additional light is provided, from 06.00 to 20.00 hours, over one end of the colony room where the mating cages and male monkeys are situated. Full accounts of the general lay-out, fixtures and procedures used in the management of the primate colony have been given by Eckstein \& Zuckerman (1957) and by Robinson (1964).

All of the female monkeys were individually caged and fed on the Modified Diet 41B (Oxoid Ltd) supplemented with fresh fruit, vegetables and various vitamins (Eckstein \& Kelly, 1966). This diet is thought to supply an adequately balanced intake of animal and vegetable protein and contains a high concentration of vitamin $B_{12}$. 


\section{Routine observations and treatments}

The menstrual cycle of each monkey was followed by routine daily visual examination of its perineum, supplemented, where necessary, by vaginal lavage. Day 1 of the menstrual cycle was recorded when menstrual blood was first observed on the perineum or in the vaginal lavage.

When menstrual bleeding was not observed within approximately 3 months of arrival, abortion or parturition, the individual monkey was given $100 \mu \mathrm{g}$ oestradiol dipropionate daily for 7 days, followed by $2 \mathrm{mg}$ progesterone daily for 5 days, both by intra-muscular injection. This treatment induced a withdrawal bleeding and invariably initiated regular menstrual cycles.

Surgical interference was always completed with full aseptic precautions, followed by routine antibiotic therapy. Major procedures involving laparotomy were performed under pentobarbital sodium anaesthesia (Nembutal, Abbott Laboratories), and phencyclidine hydrochloride (Sernylan, Parke Davis) was used for minor procedures such as radiography and trans-cervical IUD insertion.

\section{Selection of monkeys}

Throughout this series of communications, the experimental animals are identified as control and IUD monkeys. An IUD monkey is one which had been fitted with a small plastic IUD lying wholly within the uterine lumen; a control monkey is one without such an IUD.

\section{Control monkeys}

Fifty-eight control monkeys, all imported, were selected for use in the principal experiments. On arrival, eighteen were pregnant, five were recently post partum and thirty-five were non-pregnant. Two of the pregnant monkeys were subjected to hysterotomy with removal of the foetus. Two of the nonpregnant monkeys later conceived in the primate colony before entering the present series of experiments. Thus, twenty-five control monkeys were of proved fertility when they were used in the experiments.

None of the control monkeys was deliberately subjected to sham operations for the insertion of an IUD. However, an abortive attempt had been made to insert an IUD trans-cervically in ten of the control monkeys. Rupture of the endocervical canal occurred in five animals; in three of these an IUD had been inadvertently placed within the peritoneal cavity.

It must be emphasized that control observations on menstrual periodicity, ovulation and conception were recorded from monkeys that were subsequently fitted with an IUD. Three monkeys were re-used as control animals in acute experiments after their IUDs had been removed or expelled in the course of previous experiments.

\section{Preparation of IUD monkeys}

Intra-uterine devices were fitted within the uterine cavities of fifty-nine monkeys. All of these monkeys were known to have macroscopically normal genital tracts at the time the IUDs were inserted: twenty-six animals had been pregnant on arrival in the colony: five had been recently post partum: twenty- 
seven had been non-pregnant, and one nulliparous monkey had been born in the colony.

Various types of IUD were used in this study, but all were prepared from polyethylene, which contained approximately $25 \%$ of barium sulphate to render it radio-opaque. Details of the IUDs (illustrated in Text-fig. 1) are out1 ined as follows:

Type 1. Solid discs or rings (8 or $10 \mathrm{~mm}$ diameter, by 1 to $1.5 \mathrm{~mm}$ thick).

Type 2. Shortened Margulies' spirals (human pattern) (15 to $20 \mathrm{~mm}$ diameter by $2 \mathrm{~mm}$ thick).

Type 3. Specially prepared spirals of two and a half turns and similar to the Margulies' spiral (10 mm diameter by $11.2 \mathrm{~mm}$ thick).

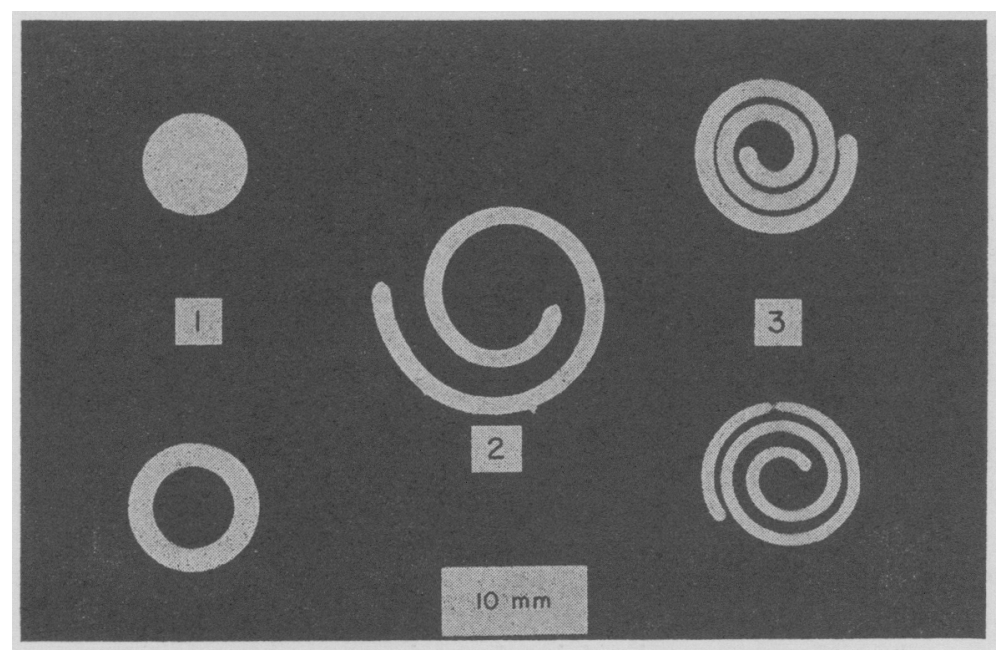

TEXT-FIG. 1. Intra-uterine devices for experimental use in the rhesus monkey.

Insertion of an IUD into the uterus was performed under general anaesthesia with aseptic precautions. Trans-cervical insertion of an IUD directly into the uterine cavity was seriously complicated by the tortuous, almost S-shaped, endocervical canal (Eckstein \& Zuckermann, 1956). Four techniques for the insertion of an IUD were tested: these can be summarized as:

Method A. At laparotomy, by incision hysterotomy in the non-pregnant monkey, or following removal of the foetus at various stages of pregnancy.

Method B. Trans-cervical insertion in parous monkeys more than 21 days post partum or post abortum (cf. Martin \& Eckstein, 1966).

Method C. Trans-cervical insertion as in B but performed within 21 days of parturition or abortion.

Method D. At laparotomy, by introducing a cannula into the uterine cavity through a small incision in the ventral surface of the uterus.

Since November 1965, the methods of IUD insertion have been standardized as either $\mathrm{C}$ or $\mathrm{D}$ using the IUD Type 3. 
The presence of the device within the uterus of an IUD monkey was checked at regular intervals by radiography and rectal palpation, and established by laparotomy or autopsy during the course of an experiment.

Insertion of IUDs

\section{RESULTS}

The results obtained with the four methods for inserting an IUD are compared in Table 1. The high proportion of failures obtained with Method B emphasized the considerable technical difficulty of passing a cannula through the endocervical canal of monkeys that were more than 3 weeks post partum. Even when it was successful, this method involved extensive trauma to the endocervical canal. By contrast, it was relatively easy to cannulate the endocervical canal in monkeys that were less than 3 weeks post partum (Method G). The method was then relatively atraumatic, but rupture of the canal occasionally occurred. Method D was the most satisfactory technique, and appeared to cause little or no damage to the uterus, as judged by subsequent examinations at laparotomy and autopsy.

TABLE 1

ANALYSIS OF ATTEMPTS TO INSERT AN INTRA-UTERINE DEVICE

\begin{tabular}{c|c|c|c|c|c|c}
\hline \multirow{3}{*}{$\begin{array}{c}\text { Method } \\
\text { of } \\
\text { insertion }\end{array}$} & $\begin{array}{c}\text { Type } \\
\text { of } \\
\text { IUD }\end{array}$ & $\begin{array}{c}\text { Total no. } \\
\text { attempts }\end{array}$ & \multicolumn{4}{|c|}{ Result of attempts at insertion } \\
\cline { 3 - 6 } & & & IUD not inserted & \multicolumn{2}{|c}{ IUD inserted } \\
\hline Abandoned & $\begin{array}{c}\text { Endocervical } \\
\text { canal ruptured }\end{array}$ & $\begin{array}{c}\text { Spontaneously } \\
\text { expelled }\end{array}$ & $\begin{array}{c}\text { Correctly } \\
\text { in place }\end{array}$ \\
\hline A & $1,2,3$ & 8 & - & - & - & $8(100 \%)$ \\
B & 2,3 & 26 & $7(27 \%)$ & $9(35 \%)$ & - & $10(38 \%)$ \\
D & 2,3 & 14 & - & $2(14 \%)$ & $2(14 \%)$ & $10(72 \%)$ \\
Total & & 32 & - & - & $1(3 \%)$ & $31(97 \%)$ \\
& & 80 & 7 & 11 & 3 & 59 \\
\hline
\end{tabular}

The Type 3 IUD was the easiest to insert and the most closely adapted to the dimensions of the monkey uterine cavity. Forty-four IUD monkeys were fitted with this type of device, eleven with Type 2 and four with Type 1 device.

\section{Menstrual periodicity}

All the available observations made before 31 st December 1967 were pooled and analysed. The results are shown in Table 2.

The control data include observations on animals that were later fitted, or had previously been fitted, with an IUD. Experiments were in progress throughout the period of observation and both the control and the IUD monkeys were subjected, in almost equal numbers, to extensive experimental surgery which continued over several separate or consecutive menstrual cycles. From January 1966 to January 1967 a deliberate attempt was made to breed from groups of control and IUD monkeys (cf. Kelly, Marston \& Eckstein, 1969). As both the control and the IUD data were collected under such variable experimental 
conditions, no attempt has been made to select the data except to exclude those menstrual cycles which were obviously abnormal.

Menstrual cycles that were less than 18 or greater than 49 days in length and others that were markedly altered as a result of surgical interference or intercurrent disease (dysentery) were excluded from the analysis. Fifty irregular cycles were excluded from the control data and seventeen from the IUD results: in each group, ten cycles were disturbed by disease or surgical interference.

Inspection of the individual records showed that there was a tendency for some monkeys to show irregular and lengthened menstrual cycles when they first entered the colony. As a rule, the length of the menstrual cycle was not obviously disturbed by surgical interference, and a consistent seasonal variation in menstrual periodicity could not be detected. There was no indication that lengthened menstrual cycles ( $>49$ days) were observed more frequently in summer than at other times of the year.

\section{TABLE 2}

ANALYSIS OF POOLED DATA ON MENSTRUAL PERIODICITY IN CONTROL AND IUD MONKEYS

\begin{tabular}{l|c|c|c}
\hline & $\begin{array}{c}\text { Total no. } \\
\text { animals }\end{array}$ & $\begin{array}{c}\text { Total no. } \\
\text { menstrual } \\
\text { cycles }\end{array}$ & $\begin{array}{c}\text { Mean length of menstrual cycle } \\
\text { ( S.E. by analysis of weighted } \\
\text { means from individual animals) }\end{array}$ \\
\hline Control & 84 & 532 & $28 \cdot 8 \pm 0 \cdot 1$ \\
IUD & 47 & 437 & $27 \cdot 9 \pm 0 \cdot 1$ \\
\hline
\end{tabular}

$P=0.001$ by Student's $t$-test for unpaired comparisons.

Table 2 shows that the difference in the mean length of the pooled menstrual cycles from control and IUD monkeys is less than 1 day. This difference is statistically significant when the $t$-test is applied either to the group means or to the means weighted for the different numbers of observations available from different monkeys. However, we consider that the difference between the menstrual periodicity of control and IUD monkeys has little or no biological significance.

The control data were biased by the inclusion of a much greater proportion of menstrual cycles recorded from recently imported monkeys. As a result of the breeding trial, a large number of control monkeys became pregnant. This restricted the number of long-term observations that could be made on control monkeys and unavoidably led to the inclusion of a more extensive series of post partum menstrual cycles in the control data. Twenty-three IUD monkeys $(49 \%)$, but only sixteen controls $(19 \%)$, provided more than ten menstrual cycles for analysis.

It has not been practicable to set up an adequately designed, carefully controlled experiment to test whether an IUD has an effect on menstrual periodicity in the rhesus monkey. However, it was possible to analyse the records of eight monkeys which had been observed both before and after the insertion of an IUD. The results are shown in Table 3. The individual monkeys 
showed very considerable within-animal and between-animal variation in the length of the menstrual cycle. Five of the eight monkeys did appear to show shorter IUD menstrual cycles than control cycles, but the differences were not statistically significant either for the individuals or for the series of paired observations.

\section{Duration of menstruation}

Quantitative observations on the duration of menstruation could not be obtained by daily visual examination, but detailed observations were completed on a series of monkeys subjected to daily vaginal lavage. There was no constant

TABLE 3

ANALYSIS OF PAIRED OBSERVATIONS OF GONTROL AND IUD MENSTRUAL GYGLES

\begin{tabular}{|c|c|c|c|c|}
\hline \multirow{3}{*}{$\begin{array}{c}\text { Monkey } \\
\text { identification } \\
\text { number }\end{array}$} & \multicolumn{4}{|c|}{ Menstrual cycles } \\
\hline & \multicolumn{2}{|c|}{ Without IUD } & \multicolumn{2}{|c|}{ With IUD } \\
\hline & $n$ & Mean $\pm S . E$. & $n$ & Mean $\pm S . E$. \\
\hline $\begin{array}{r}830 \\
945 \\
962 \\
988 \\
992 \\
1082 \\
1088 \\
1354\end{array}$ & $\begin{array}{r}11 \\
17 \\
10 \\
8 \\
8 \\
5 \\
4 \\
12\end{array}$ & $\begin{array}{l}23.18 \pm 0.38 \\
29.12 \pm 1.37 \\
27.50 \pm 1.85 \\
29.75 \pm 2.79 \\
32.50 \pm 3.54 \\
27.40 \pm 0.60 \\
26.25 \pm 0.85 \\
26.42 \pm 1.09\end{array}$ & $\begin{array}{r}16 \\
4 \\
16 \\
18 \\
18 \\
19 \\
17 \\
4\end{array}$ & $\begin{array}{l}24.25 \pm 0.86 \\
26.50 \pm 0.65 \\
24.94 \pm 0.47 \\
26.78 \pm 0.62 \\
28.11 \pm 0.56 \\
27.53 \pm 0.87 \\
28.53 \pm 1.78 \\
26.00 \pm 1.08\end{array}$ \\
\hline
\end{tabular}

Within-animal differences are not significant and for overall difference between columns $P>0.1$ (Student's $t$-test for paired comparisons).

difference in the duration of the menses in IUD monkeys (14 monkeys, 191 cycles) as compared with the controls (21 monkeys, 208 cycles). However, variable amounts of blood could be detected in the vaginal lavage at all stages of the menstrual cycle in nine IUD monkeys. This inter-menstrual bleeding continued for a varying number of cycles immediately subsequent to IUD insertion.

\section{Abnormalities of the genital tract}

Two IUD monkeys which had regular menstrual cycles for periods of 18 and 8 months after insertion of the IUD showed almost continuous vaginal bleeding after this time. At autopsy, a small endocervical polyp that was responsible for the vaginal bleeding was found in each animal. The uterus and ovaries were normal in appearance. In the first monkey, the IUD had been inserted by Method B and in the other, Method D had been used. Both monkeys had subsequently been subjected to experimental surgery which did not involve any interference with the cervix.

Apart from these cases, gross abnormalities of the genital tract were not encountered in either the control or the IUD monkeys. 


\section{DISCUSSION}

The present observations show that an IUD did not have any biologically significant effect on the periodicity or duration of menstruation in the rhesus monkey. They agree with the very limited studies of Kar, Chowdhury, Kamboj, Chandra \& Chowdhury (1965) and Kar, Kamboj, Chowdhury, Chandra $\&$ Chowdhury (1967). These results suggest that an IUD does not disturb the overall pattern of hormonal changes responsible for the menstrual cycle, but the possibility that an IUD may cause local or systemic endocrine changes which do not, in themselves, affect the periodicity of menstruation cannot be eliminated.

There is no published work available which considers the effect of an IUD on menstrual periodicity in women. Clinical experience of IUD contraception has shown that women do have regular menstrual cycles after the insertion of an IUD, but they may also be troubled by menorrhagia and intermenstrual bleeding (Tietze \& Lewit, 1962; Segal et al., 1965; WHO, 1968). Preliminary attempts have been made to analyse the hormonal status of IUD patients at various stages of the menstrual cycle (Vorys, De Neef, Boutselis, Dettmann, Scott, Stevens \& Besch, 1965; Mahesh, personal communication). This work can have little significance until it has been extended and can be related to clearly defined studies of the effect of an IUD on menstrual periodicity in women.

\section{ACKNOWLEDGMENTS}

This work was supported by a grant from the Ford Foundation, New York, whose help we gratefully acknowledge.

We are indebted to $\mathrm{Mr} \mathrm{J}$. Browning for his constant and expert collaboration throughout this series of experiments. Messrs H. Smith, F. James and G. Tonks gave invaluable help in caring for the monkeys.

\section{REFERENCES}

AsDell, S. A. (1965) Patterns of mammalian reproduction. Constable, London.

Corpman, P. A. \& Segal, S. J. (1968) Biologic effects of intra-uterine devices. Am. F. Obstet. Gynec. 100, 448.

Eckstein, P. (1967) Intrauterine contraceptive devices: the scientific background. Proc. R. Soc. Med.60, 392.

Eckstein, P. \& Keliy, W. A. (1966) A survey of the breeding performance of rhesus monkeys in the laboratory. Symp. zool. Soc. Lond. 17, 91 .

Eckstein, P. \& Zuckerman, S. (1956) Morphology of the reproductive tract. In: Marshall's Physiology of Reproduction, Vol, 1, Pt. 1, chap. 2. Ed. A. S. Parkes. Longmans Green, London.

Ecrstein, P. \& Zuckerman, S. (1957) In: UFAW Handbook on the Care and Management of Laboratory Animals, p. 663. Eds. A. N. Worden and W. Lane-Petter. UFAW, London.

GutTMacher, A. F. (1965) Intra-uterine contraceptive devices. F. Reprod. Fert. 10, 115.

KAR, A. B. (1967) Mechanism of action of intra-uterine contraceptive devices. Proc. 8th Int. Conf. plann. Parent. Santiago, p. 393.

Kar, A. B., Chowdhury, S. R., Kamboj, V. B., Ghandra, H. \& Chowdhury, A. R. (1965) Effect of an intra-uterine contraceptive device on the uterus of rhesus monkeys. Int. F. Fert. 10, 321.

Kar, A. B., KamboJ, V. P., Ghowdhury, S. R., Ghandra, H. \& Chowdhury, A. R. (1967) Long-term effect of an intra-uterine device on the uterus and Fallopian tubes of rhesus monkeys. Am. $\mathcal{J}$. Obstet. Gynec. 98, 194. 
Kelly, W. ., Marston, J. H. \& Eckstein, P. (1969) Effect of an intra-uterine device on conception and ovulation in the rhesus monkey. J. Reprod. Fert. 19, 143.

Marston, J. H. \& Kelly, W. A. (1966) The effects and mode of action of intra-uterine devices. Vet. Ree. $79,644$.

Martin, C. B. \& Eckstein, P. (1966) Transcervical uterine catheterization in rhesus monkeys. Am.J. Obstet. Gynec. 94, 415.

Ramsey, E. M. \& Harris, J. W. S. (1966) Comparison of utero-placental vasculature and circulation in the rhesus monkey and man. Contr. Embryol. 38, 60.

Robinson, J. F. (1964) The care and breeding of the rhesus monkey.J. Anim. Techns Ass. 15, 1.

Segal, S. J., Southam, A. L. \& Shafer, K. D. (1965) (Eds.) Proc. 2nd int. Conf. Intra-uterine Contraception, New York. Excerpta med. int. Congr. Ser. No. 86.

Tietze, C. 1966) Contraception with intrauterine devices. Am.J. Obstet. Gynec. 96, 1043.

Tietze, C. \& Lewit, S. (1962) (Eds.) Proc. Conf. IUCD, New York. Excerpta med. int. Congr. Ser. No. 54.

Vorys, N., De Neef, J. C, Boutselis, J. G., Dettmann, F. G., Scott, W. P., Stevens, V. C. \& Besch, P. K. (1965) Effect of intra-uterine devices on the normal menstrual cycle. Proc. 2nd int. Conf. Intra-uterine Contraception, New York. Excerpta med. int. Congr. Ser. No. 86, 147.

WHO (1968) Tech. Rep. Ser. Wld Hlth Org. No. 397.

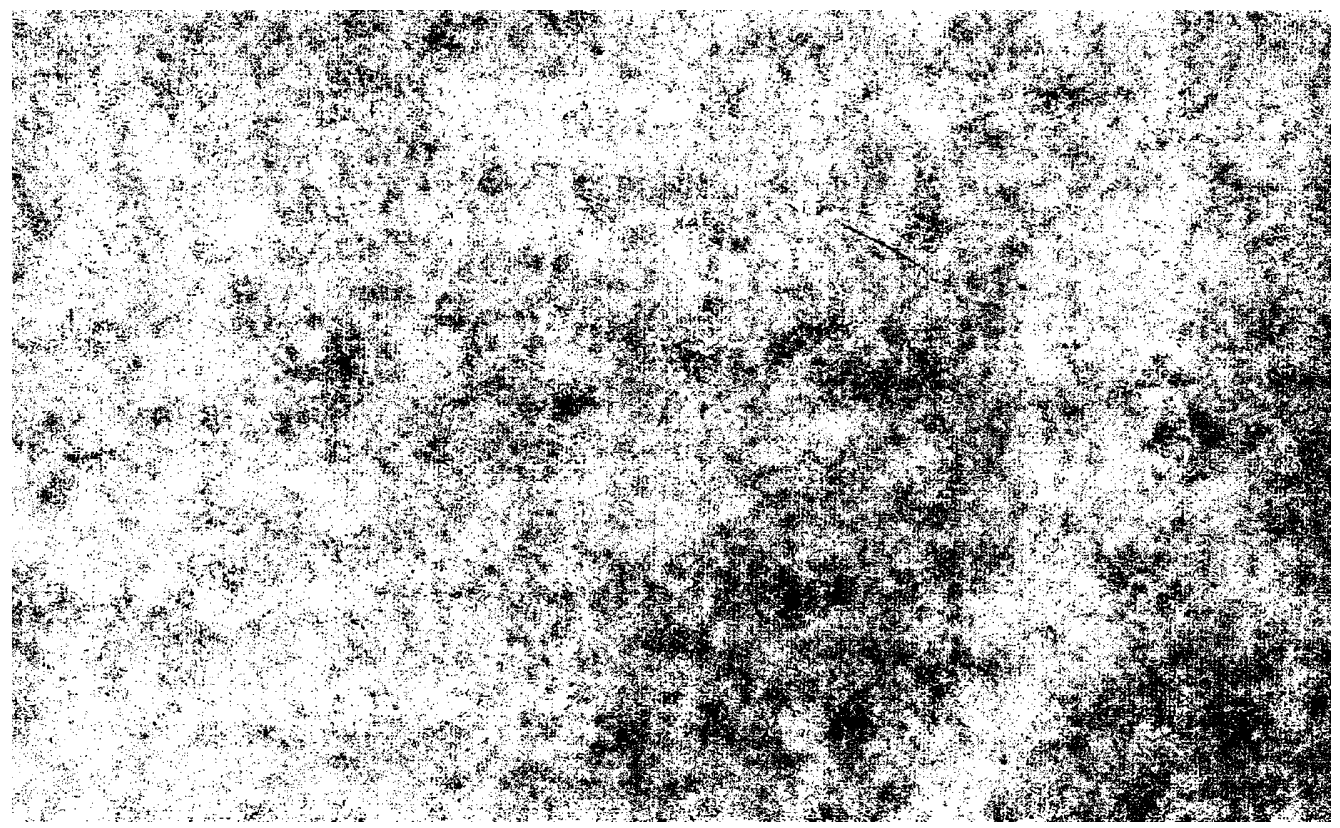

